\title{
Circulating sTWEAK Levels and Diabetic Nephropathy in Type 2 Diabetic Patients
}

\author{
Sara A. Habash, Mohamed O. Abdalla*, Fekry G. Eskandar and \\ Nashwa R. Hassan \\ Department of Clinical Pathology, Faculty of Medicine, Suez Canal University, Egypt
}

\begin{abstract}
Background: Diabetic nephropathy (DN) is one of the major complications of diabetes mellitus (DM) that leads to end stage renal disease (ESRD). There is a need for novel biomarkers for early detection and follow up of patients with DN. TNF-like weak inducer of apoptosis (TWEAK) is thought to be involved in the progression of DN through the fibroblast growth factor inducible14 (Fn14) pathway. Accordingly, blood soluble form of TWEAK (sTWEAK) could be a marker for the progression of and degree of DN. Aim: To assess the relationship between circulating sTWEAK levels and DN in type 2 diabetic patients as it could be a good potential biomarker for detection and follow up of DN patients. Patients and Methods: Sixty type 2 DM patients were selected to be 30 with DN and 30 without DN. DN patients were further divided into 20 microalbuminuric and 10 macro-albuminuric patients. Twenty normal subjects served as a control group. Patients were tested for serum creatinine, lipid prolife, glycated hemoglobin, urinary albumin creatinine ratio (ACR), estimated glomerular filtration rate (eGFR) and serum STWEAK. Results: Serum STWEAK was found to change significantly with the level of albuminuria with its lowest level in the macro-albuminuric group $(\mathrm{P}<0.0001)$. There was a significant positive correlation between serum sTWEAK and eGFR $(r=0.315$, $p$ - value $=0.014)$. Furthermore, sTWEAK showed good diagnostic value for detection of macro-albuminuria, with $90 \%$ sensitivity and $70 \%$ Specificity. Conclusion: Serum sTWEAK could be a good biomarker for detection and follow up of DN.
\end{abstract}

Key words: DN, sTWEAK, ACR, eGFR

\section{Introduction}

Diabetes mellitus (DM) is a global health problem and a major cause of morbidity and mortality around world. It is estimated that the prevalence of diabetes would rise from $6.4 \%$ ( 285 million) in 2010 to $7.7 \%$ (439 million) in $2030^{(1)}$. DM is characterized by microvascular and macrovascular sequelae. Among the microvascular sequelae, diabetic nephropathy (DN) is considered one of the prevalent and serious complications with a significant impact on morbidity, mortality and quality of life (2). It is estimated that DN develops in about one-third of all patients with diabetes during the disease course. Actually, DN is the leading cause of renal failure (RF) in de- 
veloped and developing countries(3). Diabetic nephropathy is characterized mainly by persistent albuminuria, elevated arterial blood pressure (BP), and progressive decline in the glomerular filtration rate (GFR). This could lead to an eventual progression to RF in considerable portion of patients (4). Usually, DN starts by microalbuminuria which is considered a sign of early DN while macro-albuminuria indicates progression of the disease with irreversible kidney damage (5). The microalbuminuria is considered to be the first sign to predict progression towards the end stage renal disease (ESRD) ${ }^{(6)}$. However, it's possible that some diabetics develop DN with normal albuminuria (7). Moreover since the micro-albuminuria is noticed when significant damage to glomerular function has occurred ${ }^{(8)}$, so more sensitive marker is required to predict the DN at earlier stages. Tumor necrosis factor (TNF)-like weak inducer of apoptosis (TWEAK) also known as (Apo3L, TNFSF12) is a member of the TNF superfamily (TNFSF) $^{(9)}$. Members of the TNFSF are expressed widely in various tissue types and play essential roles in immune responses, cell homeostasis, tissue repair, and inflammation ${ }^{(10)}$. TWEAK is type II transmembrane protein, but a smaller biologically active form can also be shed into the circulation as a soluble form (sTWEAK) ${ }^{(11)}$. TWEAK is ubiquitously expressed in a variety of organs, tissues and cell types such as heart, brain, pancreas, liver, kidney, skeletal muscles and adipose tissues (12). TWEAK has multiple functions with potential pathophysiological relevance that depend on the microenvironment, the cell type, and the cell state of activation. TWEAK can regulate cell proliferation, cell death, cell migration, cell differentiation, tissue regeneration, neo-angiogenesis and inflammation ${ }^{(13)}$. TWEAK has a role in injury of different organs including liver, heart, the central nervous system, gut, the vasculature, skeletal muscles, and kidney ${ }^{(14)}$. STWEAK concentration decreases progressively with increasing chronic kidney disease (CKD) stage and are lowest in patients with ESRD on chronic hemodialysis $(15,16)$. There are multiple inflammatory pathways associated with glucose metabolism, insulin sensitivity and type 2 DM (T2DM). One of these pathways could be mediated by the TWEAK. Previous studies have shown decreased serum STWEAK concentrations in type 1 diabetes (T1DM) and T2DM patients. Furthermore, it has been reported that there was an inverse association between STWEAK concentrations and fasting glucose and homeostasis model of assessment for insulin resistance (HOMA-IR) in T2DM patients on chronic hemodia-lysis(17). Some studies suggest that kidney disease and diabetes have an additive effect on decreasing sTWEAK levels ${ }^{(18)}$. Accumulating evidence from different studies has suggested a role for TWEAK pathway activation in the development of acute and chronic kidney disease. This activation contributes to both glomerular and tubulointerstitial injury in non-immune and immune mediated kidney diseases ${ }^{(19,20)}$. Fibroblast growth factor- inducible-14 (Fn14) is a famous ligand for TWEAK that mediates its function. Upregulation of the TWEAK/Fn14 pathway in DN with high levels of Fn14 in the urine of DN patients and decreased levels of TWEAK has been reported suggest dysregulation of this pathway in DN. Up to our knowledge there are no sufficient studies showing the relationship between STWEAK levels and DN, so we conducted this research to assess if there is relationship between them or not.

\section{Subjects and Methods}

Study design and participants:

A cross sectional descriptive study that included 60 type 2 diabetic patients and 
20 normal control subjects with normal HbA1c and albumin creatinine ratio (ACR). Patients were recruited from the outpatient diabetes and family medicine clinics of the Suez Canal University hospitals, Ismailia. Patients with type 2 diabetes for at least 5 years were included in our study and they were selected according to ACR and divided into two groups; 30 patients with $A C R>30 \mathrm{mg} / \mathrm{g}$ (DN group), and 30 patients with ACR $<30 \mathrm{mg} / \mathrm{g}$ (Diabetic without DN group). Patients with other chronic illnesses, kidney disease due to other causes, current fever or infection were excluded from our study.

Data and laboratory tests:

All the study population were subjected to; interview to obtain demographic data, present illness history, history of previous investigations; measurement of blood pressure and calculation of body mass index (BMI). Five milliliters of early morning fasting venous blood were withdrawn from each participant. Three milliliters were collected in a sterile plain tube and two milliliters were collected into a sterile (EDTA) tube. A spot urine sample was taken from each participant for measurement of ACR. Blood creatinine, total cholesterol, triglycerides, high density lipoprotein (HDL), low density lipoprotein (LDL), HbA1C and urine ACR were measured using the fully automated autoanalyzer (Cobas c 501, Roche Diagnostics, Mannheim, Germany). Serum sTWEAK concentrations were assessed using (Human TNFSF12 PicoKine ${ }^{\mathrm{TM}}$ ELISA Kit). Calculation of estimated glomerular filtration rate (eGFR) using the MDRD equation:

$$
\begin{gathered}
=175 \times \\
{\left[\text { plasma creatinine }\left(\frac{m g}{d l}\right)\right]-1.154 \times} \\
{[\text { age }]^{-0.203} \times[0.742 \text { if female }]} \\
\times[1.212 \text { if black }]^{(21)}
\end{gathered}
$$

\section{Statistical analysis}

Data was analyzed using SPSS software version 22.0.0.0. (SPSS, Inc., Chicago, IL, USA). Quantitative data was expressed as mean and standard deviation, while qualitative data was expressed as number and percentage. Comparisons were performed using $T$ test (for quantitative data) and chi-squared-test $\left(\chi^{2}\right)$ or Fisher's Exact test was used (for qualitative data). Oneway analysis of variance (ANOVA) was used for parametric variables and KruskalWallis test was used for non-parametric variables. The correlation between sTWEAK and other variables was performed using Pearson ( $r$ ) correlation coefficient. Diagnostic value was analyzed by Receiver operating characteristic (ROC) curve. Significance is considered at $p$ value of $<0.05$.

\section{Results}

Females were 48 subjects representing $60 \%$ of the study population while males were 32 subjects forming $40 \%$ of the study population. There was no significant difference in sex distribution between study groups (Table 1 ). Of the DN group 20 patients had ACR $<300$ while 10 patients had $A C R>300$. Accordingly, we further analysed them as 2 groups; the micro-albumiuria and macroalbuminuria groups, respective-ly. There was no statistically significant difference among diabetic groups for age, blood pressure both systolic and diastolic and for BMI (Table 2 ). Mean of age of healthy control group was $56 \pm 4.8$. There was a statistical significance between diabetic groups regarding serum creatinine $(p<0.0001)$. In normoalbuminuric group, creatinine was $0.62 \pm 0.16 \mathrm{mg} / \mathrm{dl}$ while in the microalbuminuric group it was $0.73 \pm 0.28 \mathrm{mg} / \mathrm{dl}$. The macro-albuminuric group had the highest serum creatinine $(2.68 \pm 2.45$ $\mathrm{mg} / \mathrm{dl})$. 
Table1: Sex distribution across study groups and for the whole study population

\begin{tabular}{|l|c|c|c|}
\hline Parameters & Female & Male & Total \\
\hline Group & $\mathrm{n}(\%)$ & $\mathrm{n}(\%)$ & $\mathrm{n}(\%)$ \\
\hline Diabetic normo-albuminoric & $18(60)$ & $12(40)$ & $30(100)$ \\
\hline DN & $17(57)$ & $13(43)$ & $30(100)$ \\
\hline Control & $13(65)$ & $7(35)$ & $20(100)$ \\
\hline Total & $48(60)$ & $32(40)$ & $80(100)$ \\
\hline
\end{tabular}

Fisher's Exact value $=0.417, \mathrm{p}$-value $=0.937$

Table 2. Descriptive statistics for history and examination among diabetic groups.

\begin{tabular}{|l|c|c|c|c|c|}
\hline & $\begin{array}{r}\text { Normo- } \\
\text { albuminuria }\end{array}$ & $\begin{array}{r}\text { Micro- } \\
\text { albuminuria }\end{array}$ & $\begin{array}{r}\text { Macro- } \\
\text { albuminuria }\end{array}$ & F value & p-value \\
\cline { 1 - 4 } & Mean \pm SD & Mean \pm SD & Mean \pm SD & & \\
\hline Age (years) & $56 \pm 9.02$ & $53 \pm 11.31$ & $60 \pm 6.01$ & 1.780 & 0.178 \\
\hline $\begin{array}{l}\text { Systolic BP } \\
(\mathrm{mmHg})\end{array}$ & $130.8 \pm 17.37$ & $138.3 \pm 20.54$ & $132.9 \pm 17.63$ & 1.389 & 0.258 \\
\cline { 1 - 4 } $\begin{array}{l}\text { Diastolic BP } \\
(\mathrm{mmHg})\end{array}$ & $82.5 \pm 11.43$ & $86.8 \pm 14.17$ & $79 \pm 12.87$ & 1.386 & 0.258 \\
\cline { 1 - 4 } $\mathrm{BMI}\left(\mathrm{kg} / \mathrm{m}^{2}\right)$ & $33.85 \pm 7.08$ & $34.19 \pm 6.26$ & $33 \pm 9.84$ & 0.087 & 0.916 \\
\hline
\end{tabular}

Significance at p-value $<0.05$, ANOVA test.

The eGFR had a statistical significance between diabetic groups with $\mathrm{P}$-value $<0.0001$. The normo-albuminuric group had the highest eGFR with $114.83 \pm 23.84$ $\mathrm{ml} / \mathrm{min} / 1.73 \mathrm{~m}^{2}$ and slightly decreased to $105.17 \pm 27.11 \mathrm{ml} / \mathrm{min} / 1.73 \mathrm{~m}^{2}$ in the microalbuminuric group (Table 3). Serum sTWEAK levels showed significant difference between study groups (Table 4 and figure 1). In normo-albuminuric group serum sTWEAK was $1064 \pm 579.66 \mathrm{pg} / \mathrm{mL}$ while in the micro-albuminuric group serum sTWEAK was $1407 \pm 725.97 \mathrm{pg} / \mathrm{mL}$. The macro-albuminuric group had the lowest serum STWEAK which was $420 \pm$ $378.82 \mathrm{pg} / \mathrm{mL}$ while healthy control had the highest level which was $1434 \pm 562.62$ $\mathrm{pg} / \mathrm{mL}$. Levels was around the same values for both males and females in the same group (Figure 2). Correlations of STWEAK with other variables showed a moderate positive correlation between STWEAK and eGFR (Table 5 and figure 3). Receiver operating characteristic (ROC) curve analysis for STWEAK as an indicator of albuminuria in the whole population (Figure 4) showed that the area under the curve was $33.2 \%$. The sensitivity and specificity are $40 \%$ and $35 \%$ at a cut-off point of 1202 $\mathrm{pg} / \mathrm{mL}$ of sTWEAK. We also applied ROC curve analysis for STWEAK as an indicator of macro-albuminuria in diabetic patients (Figure 5). In this situation, the area under the curve was $85 \%$ with a highly significant $\mathrm{p}$-value of $<0.001$. The sensitivity and specificity reached $90 \%$ and $70 \%$, respectively, at a cut-off point of $852 \mathrm{pg} / \mathrm{mL}$ of sTWEAK.

\section{Discussion}

DN is one of the micro-vascular complication of DM that leads to end stage renal disease. Many lines of evidence show that inflammatory pathways have an important role in the development of diabetic complications, such as DN. The relationships between inflammation and the development and progression of DN involve complex molecular networks and processes $^{(22)}$. Understanding of the roles that 
these inflammatory pathways have in the context of DN will facilitate the discovery of new biomarkers and therapeutic targets. In the current study serum sTWEAK was found to be the lowest in macro- albuminuric group, higher in normo- and micro-albuminuric groups and the highest in diabetes free group and was statistically significant ( $p$-value $<0.0001$ ) by ANOVA testing (Table 4).

Table 3. Descriptive statistics of laboratory tests among diabetic groups

\begin{tabular}{|c|c|c|c|c|c|}
\hline & $\begin{array}{c}\text { Normo- } \\
\text { albuminuria }\end{array}$ & $\begin{array}{c}\text { Micro- } \\
\text { albuminuria }\end{array}$ & $\begin{array}{c}\text { Macro- } \\
\text { albuminuria }\end{array}$ & \multirow[t]{2}{*}{ F value } & \multirow[t]{2}{*}{$\mathrm{p}$-value } \\
\hline & Mean \pm SD & Mean \pm SD & Mean \pm SD & & \\
\hline Creatinine (mg/dL) & $0.62 \pm 0.16$ & $0.73 \pm 0.28$ & $2.68 \pm 2.45$ & 22.085 & $<0.0001$ \\
\hline eGFR $\left(\mathrm{mL} / \mathrm{min} / 1.73 \mathrm{~m}^{2}\right)$ & $114.83 \pm 23.84$ & $105.17 \pm 27.11$ & $41.27 \pm 30.52$ & 21.399 & $<0.0001$ \\
\hline $\mathrm{ACR}(\mathrm{mg} / \mathrm{gm})$ & $11.33 \pm 11.31$ & $71.59 \pm 37.35$ & $2280.89 \pm 3008.79$ & 14.707 & $<0.0001$ \\
\hline Cholesterol (mg/dL) & $194 \pm 61.4$ & $201 \pm 49.63$ & $175 \pm 43.87$ & 0.751 & 0.477 \\
\hline Triglycerides $(\mathrm{mg} / \mathrm{dL})$ & $144 \pm 73.7$ & $167 \pm 76.53$ & $144 \pm 63.12$ & 1.466 & 0.49 \\
\hline $\mathrm{HDL}(\mathrm{mg} / \mathrm{dL})$ & $42 \pm 9.09$ & $40 \pm 12.26$ & $40 \pm 9.56$ & 0.639 & 0.736 \\
\hline $\mathrm{LDL}(\mathrm{mg} / \mathrm{dL})$ & $128 \pm 46.64$ & $127 \pm 43.23$ & $106 \pm 34.53$ & 1.024 & 0.366 \\
\hline $\mathrm{HbA1C}(\%)$ & $8.2 \pm 2.16$ & $8.6 \pm 2.79$ & $8.4 \pm 1.26$ & 0.215 & 0.807 \\
\hline
\end{tabular}

Significance at $p$-value $<0.05$; ANOVA test.

Table 4. sTWEAK levels in the study groups

\begin{tabular}{|l|c|c|c|c|c|c|}
\hline & $\begin{array}{c}\text { Normo- } \\
\text { albuminuria }\end{array}$ & $\begin{array}{c}\text { Micro- } \\
\text { albuminuria }\end{array}$ & $\begin{array}{c}\text { Macro- } \\
\text { albuminuria }\end{array}$ & Control & F Value & p-value \\
\hline STWEAK $(\mathrm{pg} / \mathrm{mL})$ & $1064 \pm 579.6$ & $1407 \pm 725.9$ & $420 \pm 378.8$ & $1434 \pm 562.6$ & 7.922 & $<0.0001$ \\
\hline
\end{tabular}

Data are presented as Mean $\pm \mathrm{SD}$, ANOVA test.

Table 5. Correlations of sTWEAK with the rest of study variables

\begin{tabular}{|l|c|c|}
\hline & \multicolumn{2}{|c|}{ sTWEAK $(\mathrm{pg} / \mathrm{mL})$} \\
\hline Variable & $\mathrm{R}$ & $\mathrm{p}$-value \\
\hline Systolic BP $(\mathrm{mmHg})$ & 0.017 & 0.878 \\
\hline Diastolic BP $(\mathrm{mmHg})$ & 0.014 & 0.902 \\
\hline Weight $(\mathrm{kg})$ & 0.164 & 0.147 \\
\hline Height $(\mathrm{cm})$ & 0.059 & 0.600 \\
\hline BMI $\left(\mathrm{kg} / \mathrm{m}^{2}\right)$ & 0.129 & 0.255 \\
\hline Creatinine $(\mathrm{mg} / \mathrm{dL})$ & -0.235 & 0.070 \\
\hline eGFR $\left(\mathrm{mL} / \mathrm{min} 1.73 \mathrm{~m}^{2}\right)$ & 0.315 & 0.014 \\
\hline ACR $(\mathrm{mg} / \mathrm{gm})$ & -0.200 & 0.076 \\
\hline Cholesterol $(\mathrm{mg} / \mathrm{dL})$ & 0.181 & 0.166 \\
\hline Triglycerides $(\mathrm{mg} / \mathrm{dL})$ & 0.049 & 0.709 \\
\hline HDL $(\mathrm{mg} / \mathrm{dL})$ & 0.111 & 0.397 \\
\hline LDL $(\mathrm{mg} / \mathrm{dL})$ & 0.221 & 0.090 \\
\hline HbA1C $(\%)$ & -0.134 & 0.236 \\
\hline
\end{tabular}

Post hoc testing for serum sTWEAK showed that there was a statistically significant difference between macroalbuminuric group and all of the following groups: normo- albuminuric, microalbuminuric and diabetes free group with $\mathrm{p}$-value $0.003,<0.0001$ and $<0.0001$ respectively (Figure1). 


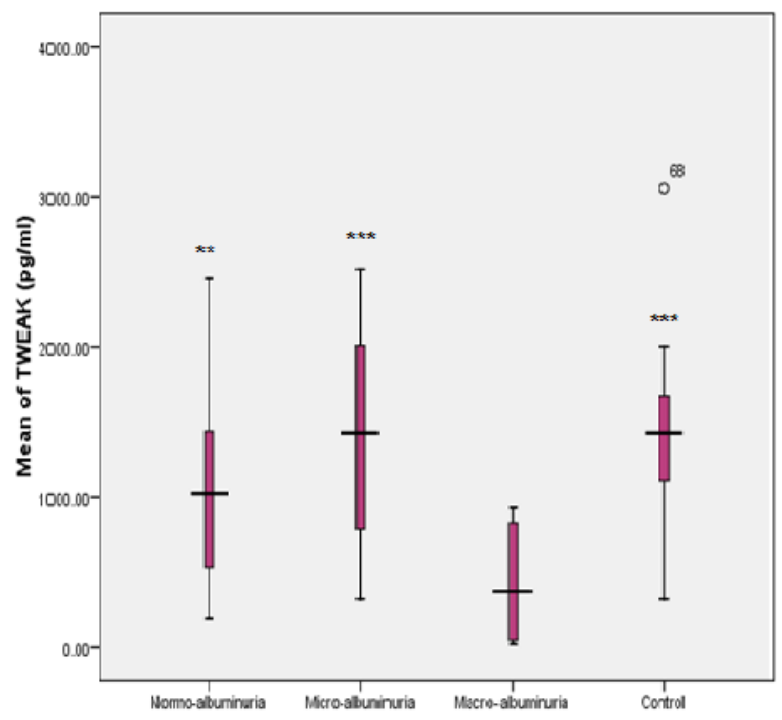

Figure 1. sTWEAK levels in the study groups.

*** $\mathrm{P}$ - value $<0.0001$ vs macro-albuminuric group;

** P-value <0.01 vs macro-albuminuric group.

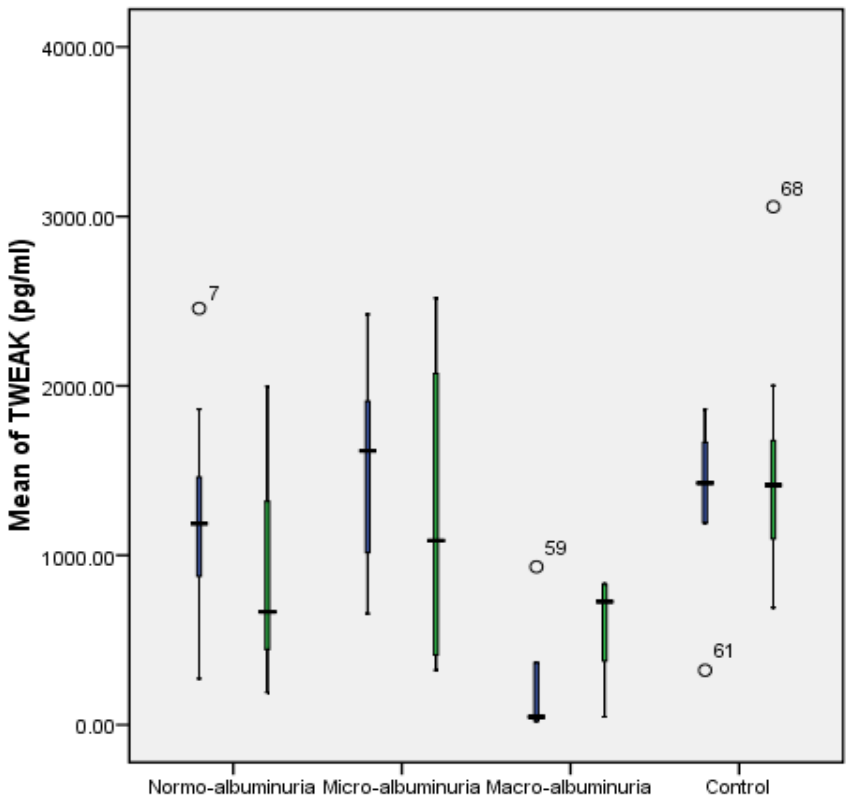

Figure 2. Gender clustered STWEAK levels in the study groups ared box blot showing STWEAK levels in each gender cluster in the study groups. T. test between both clusters in each group was not significant

This finding is in agreement with Carrero who found that sTWEAK levels were significantly lower in hemodialysis patients compared to healthy control subjects with $(\mathrm{p}-<0.0001)^{(15)}$. It was reported in a study carried out on 257 patients with stage 1-5 CKD that sTWEAK levels were decreased with advanced stages of CKD. In addition, 
low sTWEAK levels were associated with endothelial dysfunction and increased cardiovascular mortality(23). Also there was a study observed that STWEAK plasma levels were diminished and CD163 concentrations were increased and CD163/
STWEAK ratio were increased in patients with $\mathrm{CKD}^{(24)}$. Sharif and colleagues reported an elevation in soluble Fn14 (sFn14) levels in rodent models of kidney diseases and in DN patients ${ }^{(25)}$.

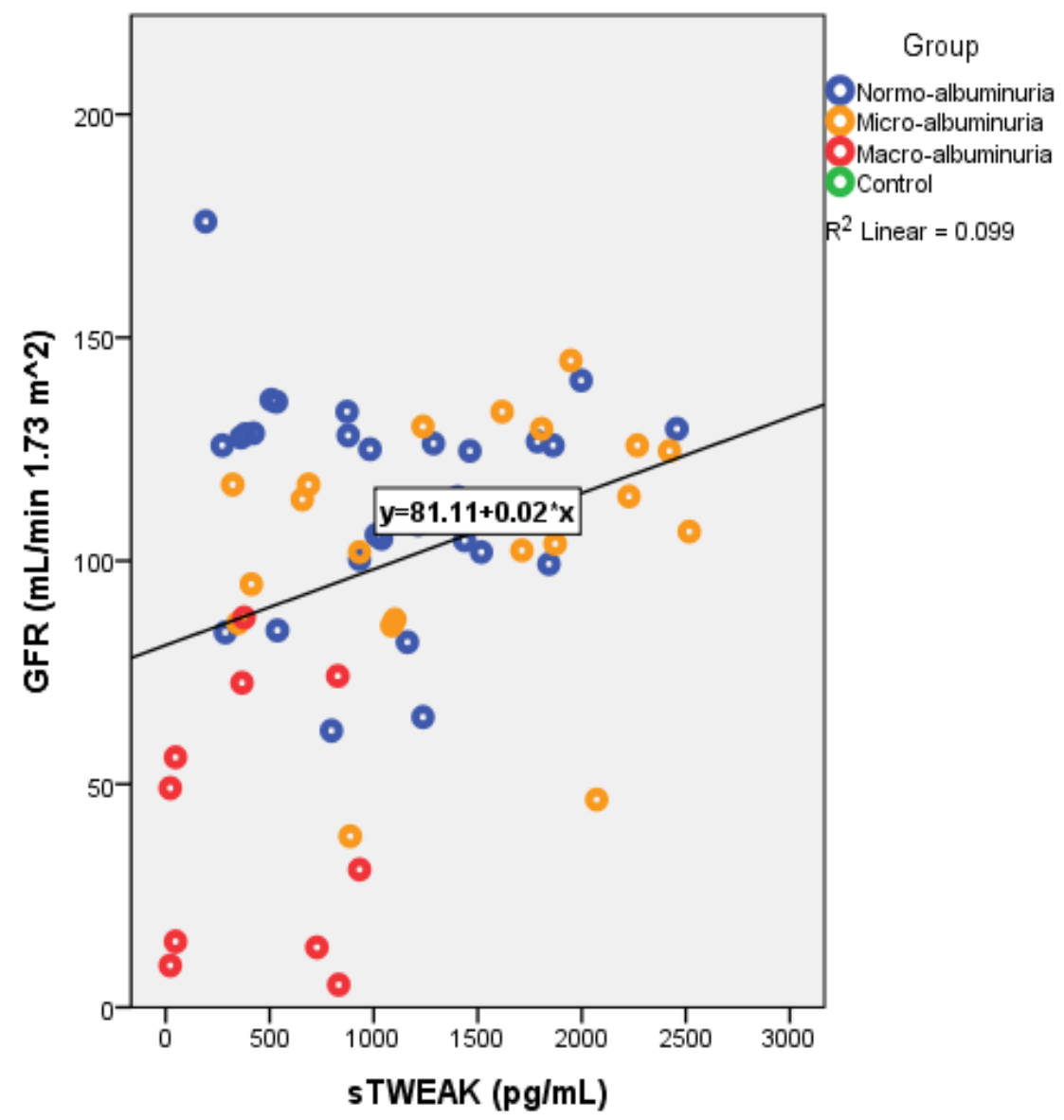

Figure 3. Correlation scatter-plot between sTWEAK and eGFR $(P<0.05)$

In this context, decreased serum STWEAK levels could be due to the elevation of sFN14 that acts as a decoy receptor. Taken together, changes in STWEAK and SFN14 levels in DN support the dysregulation of this pathway in the disease. The mechanisms by which sTWEAK concentrations are diminished in patients with $\mathrm{DN}$ are poorly understood. As noted already, a pathological role of TWEAK has been demonstrated in animal models of kidney and of atherosclerotic injury ${ }^{(26-28)}$. In this sense, TWEAK is expressed in several tis- sues, but the expression of its receptor, Fn14, is relatively low in the kidney ${ }^{(28)}$ and undetectable in the arterial wall in normal situations. However, under pathological conditions, Fn14 expression is highly upregulated in the vascular wall(29) favoring sTWEAK binding and its retention in the pathological tissues and, subsequently, decrease in its blood levels. Moreover, the diminution of STWEAK could be also related to the presence of $C D 163$, a reported scavenger receptor of STWEAK(30). 


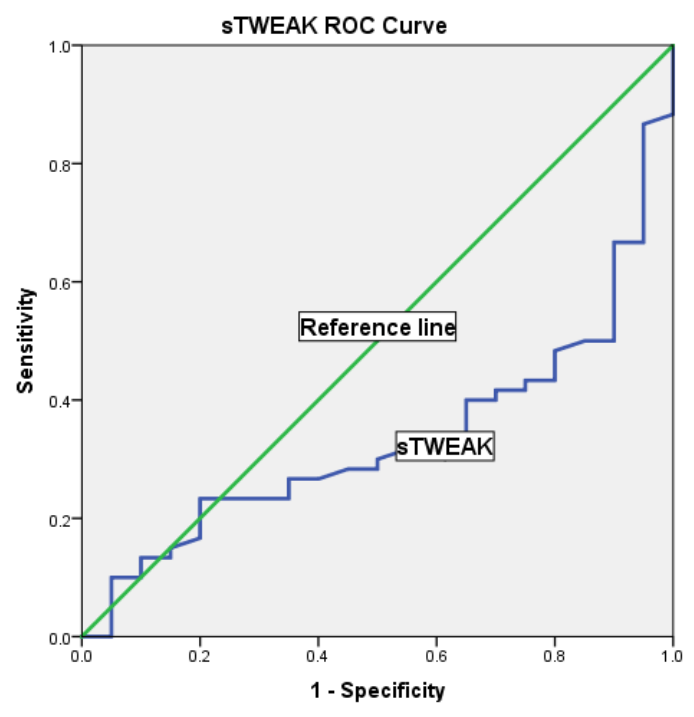

\begin{tabular}{|c|c|c|c|c|c|}
\hline Variable & Area & p-value & Cut-off point & Sensitivity & Specificity \\
\hline $\begin{array}{c}\text { STWEAK } \\
(\mathrm{pg} / \mathrm{mL})\end{array}$ & 0.332 & 0.025 & 1202 & $40 \%$ & $35 \%$ \\
\hline
\end{tabular}

Figure 4. ROC curve for STWEAK as an indicator of albuminuria

Moreover, previous data showed that CD163-expressing macrophages could bind and internalize STWEAK in vitro leading to low STWEAK levels(31). So, reduction in STWEAK concentrations could potentially reflect either Fn14 binding or CD163 mediated degradation. We found that there was a significant moderate positive correlation between serum STWEAK and eGFR, this is in accord with Yilmaz and Turkmen who found that STWEAK levels were significantly decreased when eGFR values were decreased ${ }^{(16,23,32)}$. Therefore, the decrease of STWEAK along with decreased eGFR may be associated with ongoing cell infiltration, inflammation, endothelial dysfunction, and kidney injury in DN patients. To the best of our knowledge, this is the first study that shows the association between STWEAK and DN. This association proposes the involvement of TWEAK in the molecular pathway of the development of DN. The involvement could be either through its famous ligand, Fn14, or other molecular factors. Further studies are needed to elaborate its exact role and its partners in the pathophysiology of DN which may suggest new molecular targets for treatment of or protection against DN. To assess the potential diagnostic efficiency of sTWEAK to detect DN, we performed ROC curve analysis. When ROC curve was done for serum STWEAK for diagnosis of DN determined by albuminuria ( $A C R>30 \mathrm{mg} / \mathrm{gm}$ ), The area under the curve was $33.2 \%$. The sensitivity and specificity were $40 \%$ and $35 \%$, respectively, at a cut-off point of $1202 \mathrm{pg} / \mathrm{mL}$ of STWEAK. However, when we performed ROC curve analysis for STWEAK as an indicator of macro-albuminuria (ACR > $300 \mathrm{mg} / \mathrm{g})$, the area under the curve rise to $85 \%$ with a significant $p$-value of $<0.001$. The sensitivity and specificity were $90 \%$ and $70 \%$ at a cut-off of $852 \mathrm{pg} / \mathrm{mL}$ of STWEAK. This suggests that serum sTWEAK level may not be helpful for early detection of DN, however it could be used alone or in combination with other factors to assess the severity of the disease. 


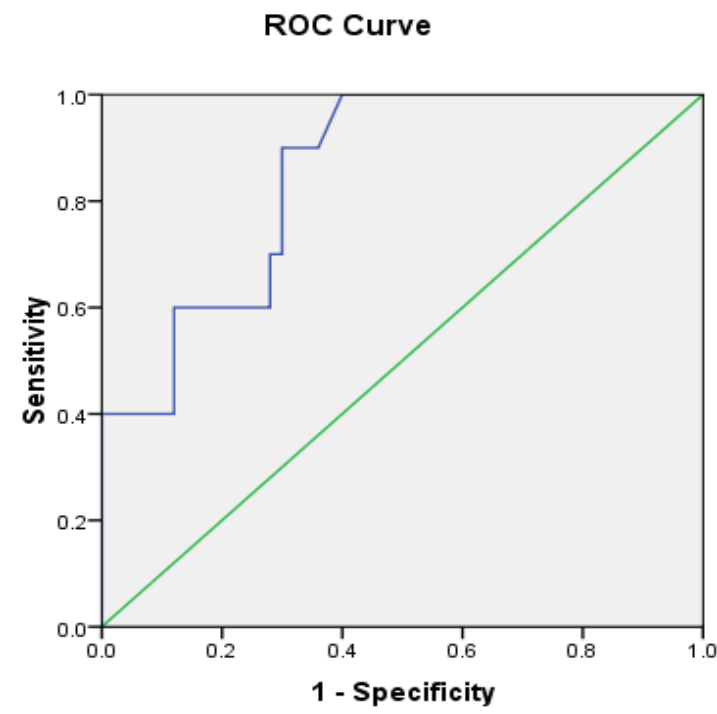

\begin{tabular}{|c|c|c|c|c|c|}
\hline Variable & Area & p-value & Cut-off point & Sensitivity & Specificity \\
\hline sTWEAK $(\mathrm{pg} / \mathrm{mL})$ & 0.850 & $\underline{\mathbf{0 . 0 0 1}}$ & 852 & $90 \%$ & $70 \%$ \\
\hline
\end{tabular}

Figure 5. ROC curve for STWEAK as an indicator of macro-albuminuria.

\section{Conclusion}

The development of DN is associated with low levels of serum STWEAK that also correlated significantly with eGFR. This sheds the light on the role of TWEAK in the pathogenesis of DN. Serum STWEAK level could be a potentially useful predictor of macro-albuminuria with high sensitivity and specificity. Most importantly, understanding the role of sTWEAK in the development of DN can suggest new therapeutic targets for disease prevention and management.

\section{Ethical Considerations}

This study was reviewed and approved by the research ethics committee of the Faculty of Medicine, Suez Canal University. A signed written informed consent was obtained from each participant of the study.

\section{References}

1. Shaw JE, Sicree RA, Zimmet PZ. Global estimates of the prevalence of diabetes for 2010 and 2030. Diabetes Res Clin Pract. 2010;87(1):4-14.
2. Hellemons ME, Kerschbaum J, Bakker SJ, Neuwirt H, Mayer B, Mayer G, et al. Validity of biomarkers predicting onset or progression of nephropathy in patients with Type 2 diabetes: a systematic review. Diabet Med. 2012;29(5):567-77.

3. Word Health Organization. Global report on diabetes2016.

4. Bichu P, Nistala R, Khan A, Sowers JR, Whaley-Connell A. Angiotensin receptor blockers for the reduction of proteinuria in diabetic patients with overt nephropathy: results from the AMADEO study. Vasc Health Risk Manag. 2009;5:129.

5. Haneda M, Utsunomiya K, Koya D, Babazono T, Moriya T, Makino H, et al. A new classification of diabetic nephropathy 2014: a report from Joint Committee on Diabetic Nephropathy. J Diabet Investig. 2015;6(2):242-6.

6. De Zeeuw D, Ramjit D, Zhang Z, Ribeiro AB, Kurokawa K, Lash J, et al. Renal risk and renoprotection among ethnic groups with type 2 diabetic nephropathy: a post hoc analysis of 
RENAAL. Kidney Int. 2006;69(9):167582.

7. Retnakaran R, Cull CA, Thorne KI, Adler Al, Holman RR. Risk factors for renal dysfunction in type 2 diabetes. Diabetes. 2006;55(6):1832-9.

8. Barratt J, Topham P. Urine proteomics: the present and future of measuring urinary protein components in disease. Can Med Assoc J. 2007;177(4):361-8.

9. Chicheportiche $\mathrm{Y}$, Bourdon PR, $\mathrm{Xu} \mathrm{H}$, Hsu Y-M, Scott $H$, Hession $C$, et al. TWEAK, a new secreted ligand in the tumor necrosis factor family that weakly induces apoptosis. J Biol Chem. 1997;272(51):32401-10.

10. Foster D, Parrish-Novak J, Fox B, Xu W. Cytokine-receptor pairing: accelerating discovery of cytokine function. Nat Rev Drug Discov. 2004;3(2):160.

11. Locksley RM, Killeen N, Lenardo MJ. The TNF and TNF receptor superfamilies: integrating mammalian biology. Cell. 2001;104(4):487-501.

12. Wiley SR, Winkles JA. TWEAK, a member of the TNF superfamily, is a multifunctional cytokine that binds the TweakR/Fn14 receptor. Cytokine Growth Factor Rev. 2003;14(3):241-9.

13. Tiller $G$, Fischer-Posovszky P, Laumen $H$, Finck $A$, Skurk $T$, Keuper $M$, et al. Effects of TWEAK (TNF superfamily member 12) on differentiation, metabolism, and secretory function of human primary preadipocytes and adipocytes. Endocrinology. 2009; 150 (12): 5373-83.

14. Sanz AB, Sanchez-Niño MD, Ortiz A. TWEAK, a multifunctional cytokine in kidney injury. Kidney Int. 2011;80(7):708-18.

15. Carrero JJ, Ortiz A, Qureshi AR, Martín-Ventura JL, Bárány $P$, Heimbürger $O$, et al. Additive effects of soluble TWEAK and inflammation on mortality in hemodialysis patients. Clin J Am Soc Nephrol. 2009;4(1):110-8.

16. Yilmaz MI, Carrero JJ, Ortiz A, MartínVentura JL, Sonmez A, Saglam M, et al. Soluble TWEAK plasma levels as a novel biomarker of endothelial function in patients with chronic kidney disease. Clin J Am Soc Nephrol 2009;4(11):1716-23.

17. Díaz-López A, Chacón MR, Bulló M, Maymó-Masip E, Martínez-González $M A$, Estruch R, et al. Serum sTWEAK concentrations and risk of developing type 2 diabetes in a high cardiovascular risk population: a nested case-control study. J Clin Endocrinol Met. 2013;98(8):3482-90.

18. Kralisch $S$, Ziegelmeier $M$, Bachmann A, Seeger J, Lössner U, Blüher $M$, et al. Serum levels of the atherosclerosis biomarker STWEAK are decreased in type 2 diabetes and end-stage renal disease. Atherosclerosis. 2008; 199 (2): 440-4.

19. Justo P, Sanz A, Sanchez-Nino M, Winkles J, Lorz C, Egido J, et al. Cytokine cooperation in renal tubular cell injury: the role of TWEAK. Kidney Int. 2006;70(10):1750-8.

20. Sanz $A B$, Izquierdo $M C$, Sanchez-Nino $M D$, Ucero AC, Egido J, Ruiz-Ortega $M$, et al. TWEAK and the progression of renal disease: clinical translation. Nephrol Dial Transplant. 2014;29 Suppl 1:i54-i62.

21. Levey AS, Coresh J, Greene T, Stevens LA, Zhang YL, Hendriksen S, et al. Using standardized serum creatinine values in the modification of diet in renal disease study equation for estimating glomerular filtration rate. Ann Intern Med. 2006;145(4):247-54.

22. Navarro-González JF, Mora-Fernández C, De Fuentes MM, García-Pérez J. Inflammatory molecules and pathways in the pathogenesis of diabetic nephropathy. Nat Rev Nephrol. 2011;7 (6):327-40.

23. Yilmaz MI, Sonmez A, Ortiz A, Saglam $M$, Kilic $S$, Eyileten $T$, et al. Soluble TWEAK and PTX 3 in nondialysis CKD patients: impact on endothelial dysfunction and cardiovascular outcomes. Clin J Am Soc Nephrol. 2011;6(4):785-92. 
24. Valdivielso JM, Coll B, Martín-Ventura JL, Moreno JA, Egido J, Fernández E, et al. Soluble TWEAK is associated with atherosclerotic burden in patients with chronic kidney disease. J Nephrol. 2013;26(6):1105-13.

25. Sharif MN, Campanholle G, Nagiec EE, Wang J, Syed J, O'Neil SP, et al. Soluble Fn14 Is Detected and Elevated in Mouse and Human Kidney Disease. PloS one. 2016;11(5):e0155368.

26. Muñoz-García B, Moreno JA, LópezFranco O, Sanz AB, Martín-Ventura JL, Blanco J, et al. Tumor necrosis factorlike weak inducer of apoptosis (TWEAK) enhances vascular and renal damage induced by hyperlipidemic diet in ApoE-knockout mice. Arterioscler Thromb Vasc Biol. 2009; 29 (12):2061-8.

27. Muñoz-García B, Madrigal-Matute J, Moreno JA, Martin-Ventura JL, LópezFranco O, Sastre C, et al. TWEAK-Fn14 interaction enhances plasminogen activator inhibitor 1 and tissue factor expression in atherosclerotic plaques and in cultured vascular smooth muscle cells. Cardiovasc Res. 2010;89(1):225-33.

28. Sanz $A B$, Justo $P$, Sanchez-Niño MD, Blanco-Colio LM, Winkles JA, Kreztler $M$, et al. The cytokine TWEAK modulates renal tubulointerstitial inflammation. J Am Soc Nephrol. 2008;19(4):695-703.

29. Muñoz-García B, Martín-Ventura JL, Martínez E, Sánchez S, Hernández G, Ortega L, et al. Fn14 Is Upregulated in Cytokine-Stimulated Vascular Smooth Muscle Cells and Is Expressed in Human Carotid Atherosclerotic Plaques. Stroke. 2006;37 (8):2044-53.

30. Bover LC, Cardó-Vila M, Kuniyasu A, Sun J, Rangel R, Takeya $M$, et al. A previously unrecognized proteinprotein interaction between TWEAK and CD163: potential biological implications. J Immunol. 2007;178(12): 8183-94.

31. Moreno JA, Muñoz-García B, MartínVentura JL, Madrigal-Matute J, Orbe J,
Páramo JA, et al. The CD163-expressing macrophages recognize and internalize TWEAK: potential consequences in atherosclerosis. Atherosclerosis. 2009;207(1):103-10.

32. Turkmen K, Tonbul HZ, Erdur FM, Toker A, Biyik $\mathrm{Z}$, Ozbiner $\mathrm{H}$, et al. Soluble TWEAK independently predicts atherosclerosis in renal transplant patients. BMC Nephrol. 2013;14(1):144. 